\title{
Markers of oxidative stress in erythrocytes and plasma during aging in humans
}

Kanti Bhooshan Pandey and Syed Ibrahim Rizvi*

Department of Biochemistry; University of Allahabad; Allahabad, India

Key words: oxidative stress, human aging, biomarkers, erythrocyte, plasma

Submitted: 10/26/09

Revised: 10/29/09

Accepted: 10/30/09

Previously published online: www.landesbioscience.com/journals/ oximed/article/10476

* Correspondence to: Syed Ibrahim Rizvi; Email: sirizvi@gmail.com
A ging is an inevitable universal biological process, which can be characterized by a general decline in physiological function with the accumulation of diverse adverse changes and increased probability of death. Among several theories, oxidative stress/free radical theory offers the best mechanistic elucidation of the aging process and other age-related phenomenon. In the present paper, we discuss the aging process and have focused on the importance of some reliable markers of oxidative stress which may be used as biomarkers of the aging process.

\section{Introduction}

Aging is a complex progressive physiological alteration of the organism which ultimately leads to death. Observational and descriptive studies performed on a large variety of aging systems have demonstrated that the main molecular characteristic of aging is the progressive accumulation of damages in macromolecules. Although different types of molecular damage accumulate at different rates and to different extents in different cells, the fact remains that there is a progressive increase in molecular heterogeneity with age. ${ }^{1}$ There are many ways to define aging and gerontologists are struggling for years to come to an agreement due to the complexity of the aging process. The aging process induces age related changes and leads to increased occurrence of many diseases. Aged individuals exhibit an inherited susceptibility to various degenerative diseases and appear less able than their young and adult counterparts to withstand physiological stress. Thus broadly, aging may be defined as an inherently complex process that is manifested within an organism at genetic, molecular, cellular, organ and system levels. ${ }^{2}$

Although the fundamental mechanisms are still poorly understood, a growing body of evidence points toward the oxidative damage caused by reactive oxygen species (ROS) as one of the primary determinant of aging. ${ }^{3}$ A certain amount of oxidative damage takes place even under normal conditions, however the rate of this damage increases during the pathological conditions like diabetes, cardiovascular diseases and cancer. ${ }^{4,5}$ An increased oxidative stress has been linked to a shortening of life span., ${ }^{2,6}$

\section{Free Radical/Oxidative Stress Theory of Aging}

There are several theories which attempt to explain the process of aging including caloric restriction, telomere theory and evolutionary theory. The oxidative stress hypothesis/free radical theory of aging proposed in 1956, updated in 2006 by Harman, ${ }^{7,8}$ offers the best mechanistic elucidation of the aging process and other age-related events. ROS are produced by aerobic cells as a byproduct of their metabolic processes as well as mitochondrial respiration. These ROS exist in the cell in balance with antioxidant molecules. A condition of oxidative stress occurs when this critical balance is disrupted due to depletion of antioxidants or excess accumulation of ROS or both i.e., when antioxidants are depleted and/or if the formation of ROS increases beyond the ability of the defenses to cope, then oxidative stress occurs and causes its detrimental 


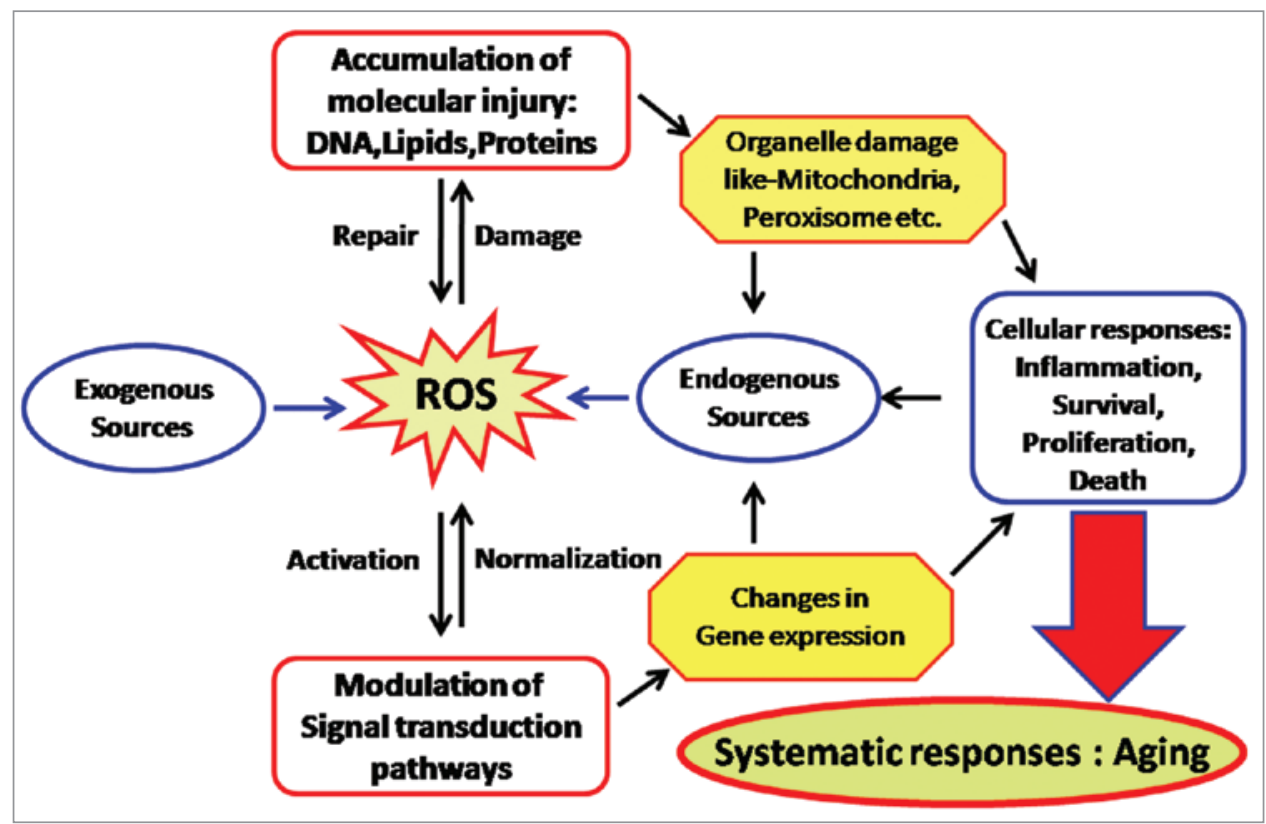

Figure I. Reactive oxygen species (ROS) generated by endogenous as well as exogenous sources, cause damage and accumulation of proteins, lipids and DNAs, when defensive (repair) mechanisms of body become weak. These ROS also modulate the signal transduction pathways. These disturbances cause organelle damage, changes in gene expression followed by altered cellular responses which ultimately results into aging.

consequences. Such stress occurs when severely adverse environmental or physiologic conditions overwhelm biological systems. Thus one rapid and clear indicator of oxidative stress is the induction of antioxidant defenses and/or increases in endogenous ROS levels.

ROS production and accumulation is a common denominator in many diseases and environmental insults and can lead to severe cellular damage leading to physiological dysfunction and cell death in virtually all aerobes. When oxidative stress occurs, cells function to counteract the oxidant effects and to restore redox balance by resetting critical homeostatic parameters. Such cellular activity leads to activation or silencing of genes encoding defensive enzymes, transcription factors and structural proteins. ${ }^{9}$ According to the free radical theory of aging, oxidative stress increases with increasing age, this condition leads to accumulation of oxidation products of lipids, nucleic acids, proteins, sugars and sterols ultimately causing cellular dysfunction and making body prone to external deleterious agents (Fig. 1).

In present review we evaluate some reliable and reproducible biomarkers of oxidative stress in human plasma and erythrocytes which are being increasingly used in studies monitoring redox changes with age. The review provides current knowledge of the use of erythrocytes as model cells for the study of aging.

\section{Erythrocytes and Plasma: Model System of Human Aging}

Though many model systems are frequently used to study the biochemical alterations during aging as well as the condition of oxidative stress including the tissues from various parts of the body, erythrocytes or red blood cells get superiority amongst them. Erythrocytes are the most common type of blood cells and are the vertebrate body's principal means of delivering oxygen from the lungs or gills to body tissues via the blood (Fig. 2). Red blood cell along with its membrane has always been an important medium for the study due to the important role it plays in varied physiological and metabolic processes. ${ }^{10-12}$ Erythrocyte has been increasingly studied because it is the easiest available human cell type. The erythrocyte has been modified by evolutionary forces into a highly specialized cell that is mainly responsible for providing oxygen to tissues and partly excrete carbon dioxide from waste. ${ }^{13}$ Red blood cells are capable of extreme changes in shape. Due to their flexibility, red blood cells can easily squeeze through capillaries much narrower than their diameter and can recover rapidly to their original shape. Mature red blood cell is a biconcave disc shaped with a diameter of 8 micron and thickness of 2 micron having an average life span of $120 \pm 20$ days. ${ }^{14}$ Due to the absence of cell organelles particularly nucleus and mitochondria, red blood cell loses its ability to synthesize amino acids and fatty acids and thus red blood cell have a limited capacity of metabolism barely enough to survive its life span. Red blood cells are continuously being removed from the circulation and to maintain their adequate number they are regularly being formed from the bone marrow in accordance with their rate of removal by reticulo-endothelial cell. ${ }^{14}$

There is no dispute that erythrocytes have a definite lifespan in all animal species investigated so far, and there is little dispute on the length of the species-specific lifespan. ${ }^{15}$ It implies that, as in other cells, life and death are well regulated for erythrocytes, in spite of their lack of capacity for protein synthesis. During aging the erythrocyte volume decreases with time, with an increase in density especially during the first, and a decrease in hemoglobin 


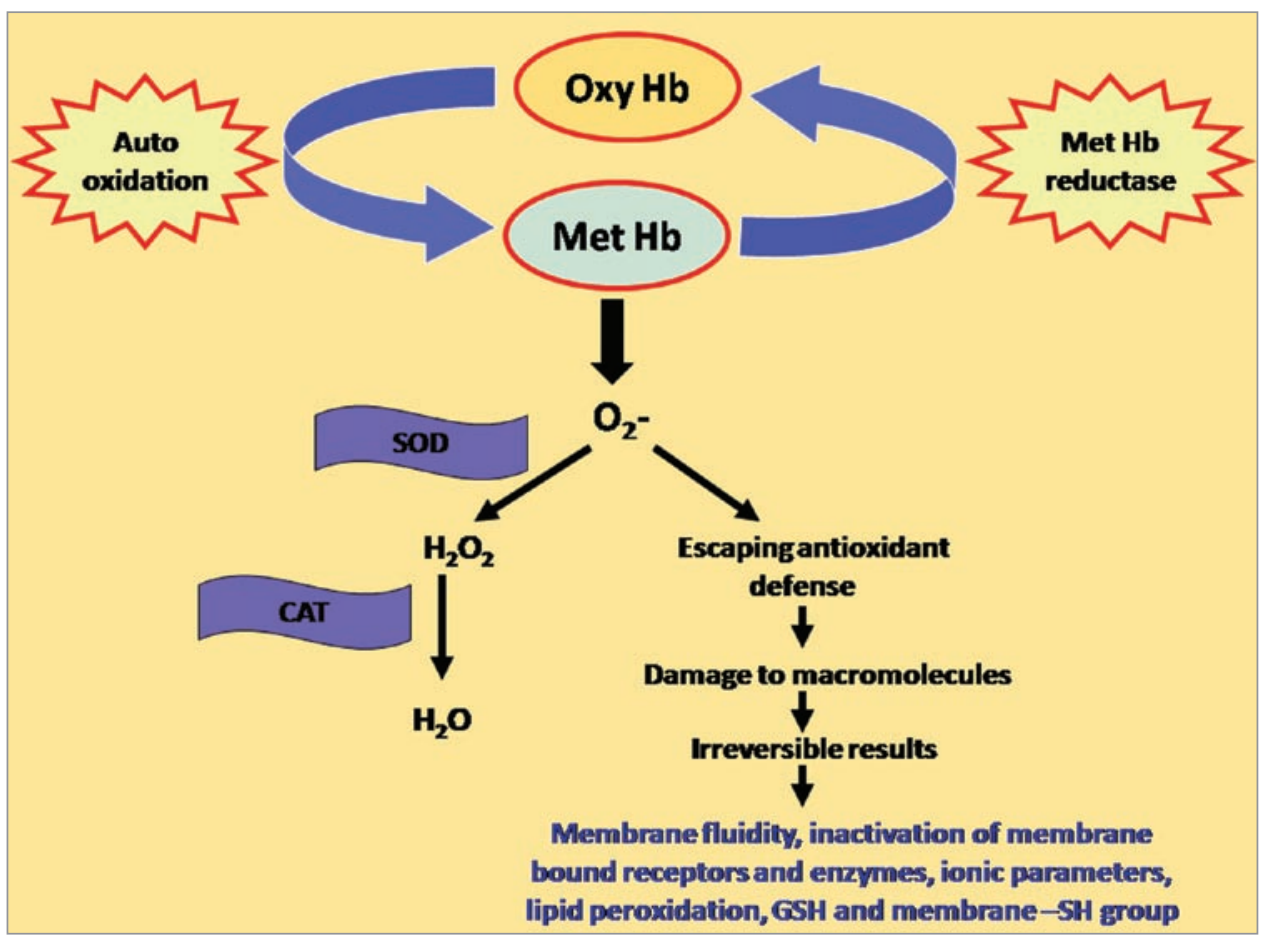

Figure 2. Development of oxidative stress in erythrocytes. Hb; hemoglobin, SOD; superoxide dismutase, CAT; catalase. Under normal conditions, reactive oxygen radicals are buffered by endogenous defensive enzymes i.e., superoxide dismutase and catalase but due to reduced reducing/antioxidant capacity during aging or in other pathological conditions, reactive oxygen radicals escape and destroy the macromolecules, which ultimately results in altered erythrocytic behavior.

content especially during the second part of the lifespan. ${ }^{16}$ These changes are associated with a loss of cholesterol and phospholipid and a linear decrease in the mean surface area of $20 \%$, which all point towards a loss of membrane constituents during aging. This loss could be readily explained through the formation of microvesicles by erythrocytes of all ages with vesicles derived from older erythrocytes containing more hemoglobin. Immunological analysis of these vesicles by flow cytometry and immunoblotting revealed that a portion, but not all of these vesicles contain $\operatorname{IgG}$ at their surface, expose phosphatidylserine, and may contain breakdown products of band 3 that are also found on the old erythrocytes. High performance liquid chromatography (HPLC) analysis showed that the hemoglobin composition of these vesicles resembles that of the old erythrocytes. ${ }^{17}$

\section{Biochemical Parameters of Aging}

During the whole life the organism is confronted with oxidative stress on one side from intrinsic origins as the mitochondrial power generation is leaking ROS/reactive nitrogen species (RNS) and on the other side from extrinsic origins. ${ }^{18,19}$ Various methods on diverse systems have been documented to study the various markers of oxidative stress and aging. However most of the biomarkers get influenced by several factors such as life style, nutrition and types of models. Less reproducibility adds another drawback to consider most of the paramerters as marker of stress. For these reasons there is a critical need for well-validated parameters that yield absolute quantitative data that can be used on multiple systems. The widespread application of such techniques would provide valuable data on the relative importance of different oxidants, and information of the absolute importance of damage to different target biomolecules. In present section we have explained only those parameters which are most reliable, reproducible and provide a correct assessment of the extent of oxidative stress.

\section{Reducing Power/Antioxidant Capacity of Plasma}

Antioxidant capacity of plasma is the primary measure and marker to evaluate the state and potential of oxidative stress in aging and other aging-induced pathological events such as diabetes, cardiovascular diseases and cancer. Since imbalance between antioxidant and oxidants generates the condition of oxidative stress, estimation of the reducing power/antioxidant capacity plasma is the first step in the prediction of oxidative stress in aging process. A number of methods has been used to measure total antioxidant capacity in vitro. These methods are mostly based on quenching of stable free radicals such as 1,1-diphenyl-2-picrylhydrazyl free radical $\left(\mathrm{DPPH}^{\circ}\right),{ }^{20} \quad 2,2$-azobis-3-ethylbenzthiazoline-6-sulfonic acid (ABTS) by antioxidants; ${ }^{21}$ inhibition of lipid peroxidation; $; 2$ fluorimetric measurement of h-phycoerythrin (in the oxygen radical absorbance capacity assay (ORAC)). ${ }^{23}$ These assays are useful due to their sensitivity and minimal sample preparation and thus are widely used in biochemical analysis of clinical samples. ${ }^{24}$ However; most of them are time consuming and utilize expensive chemicals and/or instrumentation. The FRAP (ferric reducing ability of plasma) assay developed by Benzie and Strain ${ }^{25}$ 
gets superiority because it is not dependent on the enzymatic/non-enzymatic method to generate free radical prior to evaluation of the anti-radical activity of plasma. The FRAP assay offers a putative index of antioxidants, or reducing potential of biological fluids and is simple, convenient, less time consuming and reproducible.

The correlation between antioxidant capacity and oxidative damage during aging has been reported in several tissues in different species, ${ }^{26,27}$ however data on changes of oxidative stress markers in plasma and erythrocytes of healthy populations during aging are few and sometimes contradictory. ${ }^{28,29}$ A study carried out in our laboratory on 80 normal healthy subjects of both genders between the ages of 18 and 85 years, showed that there was a significant decrease in reducing potential of plasma as a function of human age. ${ }^{30}$

Many factors including dietary polyphenols $^{31}$ influence the extent of reducing/antioxidant potential plasma. In 1998, Cao and co-workers ${ }^{32}$ investigated the responses in serum total antioxidant capacity following consumption of strawberries (240 g), spinach (294 g), red wine $(300 \mathrm{ml})$ or vitamin $\mathrm{C}(1,250 \mathrm{mg})$ in eight elderly women. The results showed that the total antioxidant capacity of serum determined as ORAC, trolox equivalent antioxidant capacity (TEAC) and FRAP, using the area under the curve, increased significantly by $7-25 \%$ during the $4 \mathrm{~h}$ period following consumption of red wine, strawberries, vitamin $\mathrm{C}$ or spinach. Ferric reducing ability of plasma, as an index of total antioxidant capacity of plasma was found to be enhanced significantly in suckling rats pretreated either with vitamin $\mathrm{K} 1$ or menadione (vitamin K3) at a dose of $15 \mathrm{mg} / \mathrm{kg}$ b.w./3 days as reported by Hadi et al. ${ }^{33}$ The effect of vitamin K1 on FRAP was dose-dependent and it was inversely related to the formation of lipid peroxidation products in plasma as judged by thiobarbituric acid reacting substances (TBARS). ${ }^{28}$ These results suggest that the drug-related induction in FRAP occurs only in immature animals as a part of protective mechanism against lipid peroxidation products generated in plasma. Recently $\mathrm{Li}$ and co-workers ${ }^{34}$ reported a decrease in total antioxidant capacity and effect of synthetic oligosaccharides on antioxidant enzymes and lipid peroxidation in aged mice. Thus measurement of the reducing/antioxidant potential is the primary biochemical approach towards evaluation of oxidative stress during aging.

\section{Extent of Erythrocyte Lipid Peroxidation}

Lipids are the important constituents of membranes and function as steroid hormones, retinoic acids and prostaglandins. Unstable carbon radicals from fatty acids can rearrange to short alkanes and conjugated dienes which are exhaled or react with oxygen further to peroxyl radicals and finally by hydrogen abstraction to result in lipid hydroperoxides (Fig. 3). The first oxidation products are limited in their function as they are either volatile or highly reactive. Some of them can easily react to secondary oxidation products like malondialdeyhde (MDA), 4-hydroxy-2,3-trans-nonenal (HNE), isoprostanes or oxysterols. $^{35}$ These secondary oxidation products influence gene expression and protein synthesis and these can lead to further damage by cross linking proteins.

Lipid peroxidation was first studied in relation to the deterioration of foods in 1930s, when the study on the chemistry of free radical reactions made remarkable advancements. ${ }^{36,37}$ With increasing evidence showing the involvement of free radicals in biology, ${ }^{4}$ lipid peroxidation has received renewed attention from wider viewpoints in the fields of chemistry, biochemistry, nutrition and medicine. Later studies revealed that just like proteins, carbohydrates and nucleic acids, lipids are targets of various reactive oxygen and nitrogen species and oxidized to give a diverse array of products. ${ }^{38}$ Studies have revealed that lipid peroxidation severely affects biomembranes. It induces disturbance of fine structures, alteration of integrity, fluidity, permeability and functional loss of biomembranes and also modifies low density lipoprotein (LDL) to proatherogenic and proinflammatory forms, and generates potentially toxic products. ${ }^{39}$ Lipid peroxidation products have also been shown to be mutagenic and carcinogenic ${ }^{40}$ and has been implicated as the underlying mechanisms in numerous disorders and diseases such as cardiovascular diseases, cancer, neurological disorders and also in aging. ${ }^{41,42}$

One of the most often used biomarker to investigate the oxidative damage on lipids is the measurement of MDA, the major lipid peroxidation product, this can react with the free amino group of proteins, phospholipids and nucleic acids leading to structural modification, which can induce dysfunction of immune systems. A high level of lipid peroxidation products can be detected in cell degradation after cell injury or disease. ${ }^{43,44}$ Lipid peroxidation is a free-radical chain reaction which is accelerated by ROS. Cell membranes are phospholipid bilayers with extrinsic proteins and are direct targets of lipid oxidation. As lipid oxidation of cell membranes increases, the polarity of lipid-phase surface charge and the formation of protein oligomers increase, and molecular mobility of lipids, number of SH (thiol) groups, and resistance to thermo-denaturation decrease. Recent findings have emphasized the importance of lipid peroxidation in relation to the role of caloric restriction and the extension of longevity. ${ }^{45}$ Long-lived mammals and birds possess low degrees of unsaturation in their cellular membranes; this leads to lower levels of lipid peroxidation and lipoxidation-derived protein modification in long-lived species. ${ }^{45}$

The measurement of MDA according to the method of Esterbauer and Cheeseman, ${ }^{46}$ is very easy to perform, fast as well as cheap. The erythrocyte membrane is prone to lipid peroxidation under oxidative stress that involves cleavage of polyunsaturated fatty acids at their double bonds leading to the formation of MDA. The study carried out in our laboratory on a group of normal healthy young, middle and old aged people of both sexes, showed a significant positive correlation between the erythrocyte MDA level and human age. ${ }^{42}$ Similar age-dependent increase in erythrocyte MDA has also been reported for European subjects; ${ }^{47}$ however, we find that the increase in MDA in the Indian population is much greater than that reported in European subjects. This observation is strengthened by the finding that healthy older free-living European subjects do not appear to be exposed to an acute oxidative stress. 
In the continuation of study, the correlation of antioxidant activity of plasma of the same volunteers has been also compared with the MDA concentration. The increase in MDA correlated significantly with decrease in the antioxidant capacity of the plasma during human aging, confirming that the decrease in antioxidant power in body is a reason for increased oxidative stress during aging. ${ }^{42}$ Since the measurement of MDA is easy and fast to perform and the results are very reproducible, it is one of the most important biomarkers for the evaluation of the status of lipid peroxidation and is a biomarker of aging.

\section{Protein Oxidation}

The main molecular characteristic of aging is the progressive accumulation of damages in macromolecules. Proteins are likely to be major targets, as a result of their abundance in cells (proteins compose approximately $70 \%$ of the dry mass of most cells), plasma, and most tissues, and their rapid rates of reaction both with many radicals and with other oxidants. ${ }^{48}$ Proteins are one of the major categories of age-related damage in macromolecules, which have been observed during various cells, tissues and organs. ${ }^{1}$ ROS can lead to oxidation of amino acid residue side chains, formation of protein-protein cross-linkages, and oxidation of the protein backbone resulting in protein fragmentation. ${ }^{49}$ One of the greatest challenges in aging research today is the identification of specific cause of oxidative modification and accumulation of macromolecules specifically proteins. Oxidative damage leads to loss in specific protein function, since proteins have unique biological functions, there are often unique functional consequences resulting from their modification. It is estimated that almost every third protein in a cell of older animals is dysfunctional as enzyme or structural protein due to oxidative damage. ${ }^{50}$ Therefore, the measurement of the protein oxidation is a clinically important factor for the prediction of the aging process and age-related diseases.

Oxidation of proteins can lead to a whole variety of amino acid modifications. Action of chloraminated oxidants, mainly hypochlorous acid and chloramines,

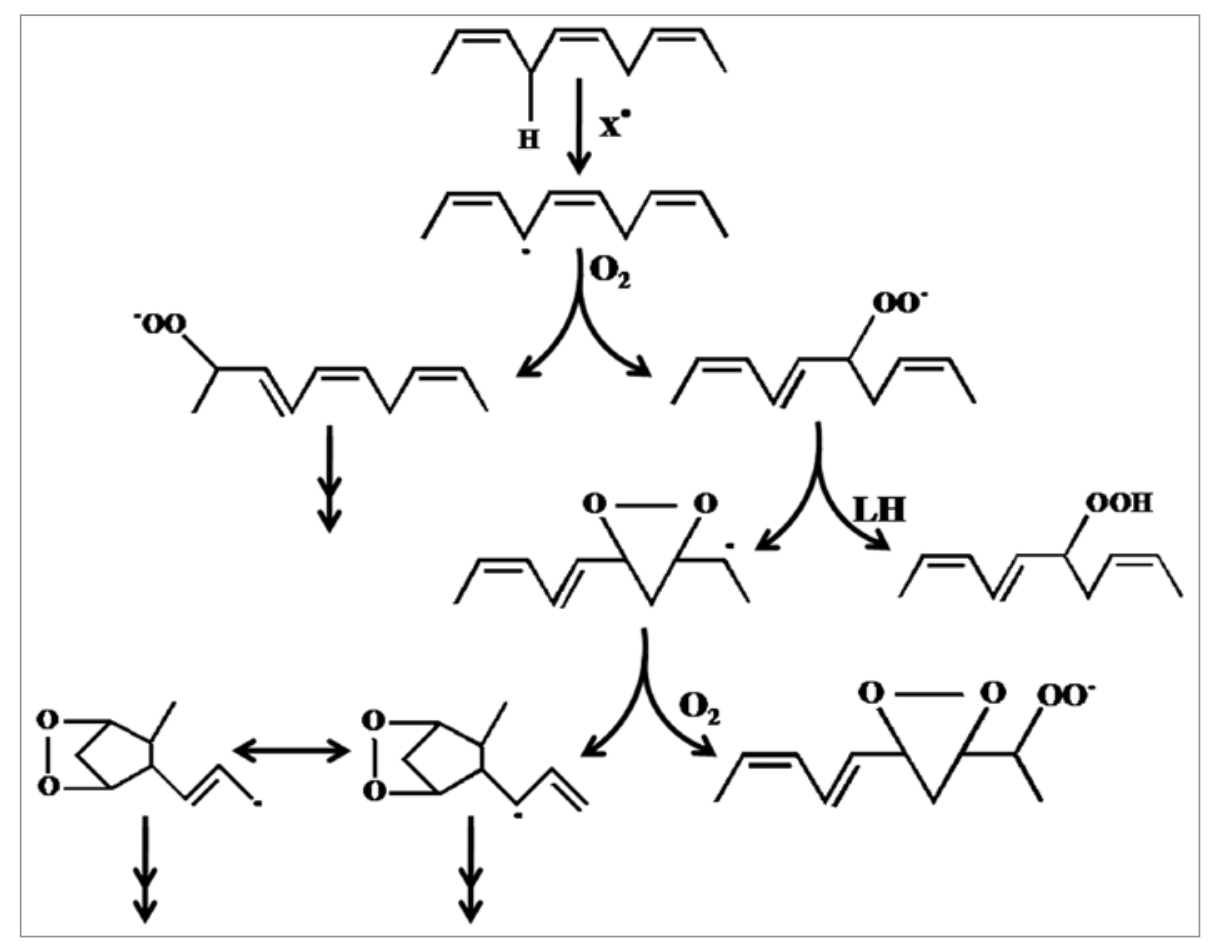

Figure 3. Pathways of free radical mediated lipid peroxidation, proceeds by a chain mechanism, that is, one initiating free radical can oxidize many molecules of lipids. Chain progression is carried by lipid peroxyl radicals independent of the type of chain-initiating free radicals. The major reactions include abstraction of bisallylic hydrogen from polyunsaturated fatty acids to give carboncentered radicals which rearranges to more stable cis,trans-pentadienyl radicals, addition of oxygen to the pentadienyl radical to give lipid peroxyl radicals, release of oxygen from the peroxy radical to give oxygen and pentadienyl radicals, which rapidly react with oxygen to give a thermo chemically more stable trans, trans form preferentially than cis, trans form and intramolecular addition of the peroxyl radical to the double bond to yield bicyclic prostaglandin-type products. The important chain propagation step is the abstraction of bisallylic hydrogen from lipids by lipid peroxyl radicals to give conjugated diene lipid hydroperoxide and new lipid radicals, which continues another chain reaction (Niki et al. 2009).

produced by myeloperoxidase in activated neutrophils, forms dityrosine containing cross-linked protein products known as advanced oxidation protein products (AOPPs) and are also considered as bio markers to estimate the degree of oxidative modifications of proteins. ${ }^{51}$ The attack of ROS against proteins modifies amino acids; lysine, arginine, proline and histidine residues generating carbonyl moieties, which has been identified as an early marker for protein oxidation and is used as a measure of protein damage. ${ }^{52}$ Generation of protein carbonyl derivatives occurs by oxidative modifications of proteins either by the $\alpha$-amidation pathway or by oxidation of glutamyl side chains, which leads to formation of a peptide in which the $\mathrm{N}$-terminal amino acid is blocked by an $\alpha$-ketoacyl derivative. However, direct oxidation of lysine, arginine, proline and threonine residues may also yield carbonyl derivatives. ${ }^{49}$ In addition, carbonyl groups may be introduced into proteins by reactions with aldehydes (4-hydroxy-2-nonenal, malondialdehyde) produced during lipid peroxidation ${ }^{53}$ or with reactive carbonyl derivatives (ketoamines, ketoaldehydes, deoxyosones) generated as a consequence of the reaction of reducing sugars or their oxidation products with lysine residues of proteins. ${ }^{54}$

Some protein damage is reversible, such as peroxiredoxin inactivation, methionine sulphoxide formation, s-nitrosylation. Other damage, for example oxidation of side-chains to carbonyl residues, appears irreversible and the protein is destroyed. ${ }^{4}$ The presence of carbonyl groups in proteins has therefore been used as a marker of ROS-mediated protein oxidation. Erythrocytes are highly susceptible to 
oxidative damage due to the high cellular concentration of oxygen and hemoglobin, a potentially powerful promoter for the oxidative processes. ${ }^{55}$ Recently we have shown an increased level of protein carbonyls in human erythrocyte membrane during oxidative stress condition. ${ }^{56,57}$ An age related increase in the protein carbonyl concentration was reported for tissues like heart, muscle or brain ${ }^{58,59}$ as well as in plasma of healthy people. ${ }^{47,60,61}$

Except protein carbonyls, AOPPs, branched-chain amino acids and lipofuscin are other markers of oxidative damage of proteins moieties however use of protein carbonyls as index of oxidative stress has some advantages in comparison with the measurement of other oxidation products because of the relative early formation and the relative stability of carbonylated proteins. ${ }^{62}$ Age dependent increase in protein carbonyl level is direct evidence towards the fact that oxidative stress increases during aging, as the antioxidant capacity of the body falls. Although, proteolytic systems exist to remove oxidized proteins, protein oxidation is still an excellent biomarker of oxidative stress due to the relative long half-life of such oxidized proteins. Following severe oxidative stress, the decrease in the proteolytic degradation and accumulation of mis-folded proteins may be the cause and/or the consequence of many disorders and aging.

\section{Reduced Glutathione and Membrane -SH Groups}

Reduced glutathione (GSH) is a major intracellular non-protein -SH compound and is accepted as the most important intracellular hydrophilic antioxidant. ${ }^{27}$ GSH has many biological functions, including nutrient metabolism, and regulation of cellular events such as gene expression, DNA and protein synthesis, cell proliferation and apoptosis, signal transduction, cytokine production and immune response, and protein glutathionylation. GSH also plays a role in maintenance of membrane protein - $\mathrm{SH}$ groups in the reduced form, the oxidation of which can otherwise cause altered cellular structure and function. Glutathione deficiency has been reported in many diseases such as Kwashiorkor, Alzheimer disease, Parkinson disease, liver disease, cystic fibrosis, sickle cell anemia, AIDS, cancer, heart attack, stroke and diabetes. ${ }^{63}$ Glutathione system is the most important endogenous defense system against oxidative stress in body. Under oxidative conditions GSH is reversibly oxidized to glutathione disulfide (GSSG). A recent study on age-related changes in GSH in rat brain suggests a significant age-related reduction in the GSH level in all regions of the brain, associated with an increase in GSH oxidation to GSSG and decrease in the GSH/GSSG ratio. ${ }^{64}$ The GSH/GSSG redox, per se, functions in redox signaling and control as well as antioxidant protection. The thiol/disulfide redox states may provide central parameters to link environmental influences and progression of changes associated with aging. ${ }^{65}$

GSH plays a key role in protecting cells against electrophiles and free radicals. This is due to the nucleophilicity of the -SH group and to the high reaction rate of thiols with free radicals. ${ }^{66}$ Stress resistance of many cells is associated with high intracellular levels of GSH. ${ }^{67-69}$ Cells containing low levels of GSH were found to be much more sensitive to the effect of irradiation and stress than controls. ${ }^{67}$ Indeed, GSH can act directly as a free radical scavenger by neutralizing $\mathrm{HO}^{\circ}$, or indirectly by repairing initial damage to macromolecules inflicted by $\mathrm{HO}^{\bullet}{ }^{70}$ There is ample evidence that thiols protect molecules from radiation injury, mainly by hydrogen donation, which can restore damaged molecules to their original state. ${ }^{71}$ Moreover, GSH is a substrate or a cofactor for a number of protective enzymes, such as GSH peroxidase, the GSH S-transferases, or the glayoxalase. $^{70}$

Different studies have pointed out the importance of determination of blood glutathione for both pathological and physiological purposes. Herebergs et al. ${ }^{72}$ have reported that cancer patients are more likely to respond to treatment if their erythrocyte GSH and, by inference, tumor GSH concentrations are low. There are alterations of GSH reductase activity in peripheral-blood erythrocytes in such diseases as hypothyroidism and riboflavin deficiency ${ }^{73,74}$ Exhaustive physical exercise causes changes in the glutathione status of blood, liver and muscles. ${ }^{75}$
A recent study on Indian populations of different age groups revealed an agedependent decline in intracellular-reduced GSH concentration which correlates with the total antioxidant capacity of the plasma. ${ }^{42}$ Gil et al. ${ }^{47}$ reported a slow but significant decline of the intra erythrocytic GSH concentration with aging in European subjects. Similar observations have been reported by Erden-Inal et al.; ${ }^{76}$ however, another study on European subjects did not detect any change in GSH levels. ${ }^{77}$ Human erythrocytes are rich in - $\mathrm{SH}$ functions: the importance of the erythrocyte $-\mathrm{SH}$ group in overall cellular redox balance has been emphasized. ${ }^{78}$

Membrane oxidative damage has a considerable effect on membrane mechanical properties. Membrane - $\mathrm{SH}$ group oxidative damage may be an important molecular mechanism inducing changes in the membrane microelasticity or whole cell deformability under conditions of physiological and pathological oxidative stress. ${ }^{79}$ The altered redox balance with increasing age may affect the activity of virtually any protein since essentially all proteins contain cysteine (Cys) and methionine (Met), amino acids that are subject to oxidation reduction changes. Studies from our lab reveled that both, the reduced glutathione and membrane - $\mathrm{SH}$ group are important markers of oxidative stress and it was reported that their concentrations are significantly low in higher age group humans in comparison to younger as well as middle aged humans. ${ }^{42}$

\section{Plasma Membrane Redox System}

The plasma membrane regulates numerous aspects of cell physiology and signaling and also protects cells against oxidative stress. Plasma membrane also plays fundamental roles in regulating cellular ion homeostasis, nutrient transport, cell adhesion and signal transduction. The proteins and lipids involved in these functions of the plasma membrane are susceptible to oxidative modifications that may contribute to the dysfunction and degeneration of neurons that occur in aging and neurodegenerative disorders. ${ }^{80}$ For example, lipid peroxidation and oxidative modifications of plasma membrane ion-motive ATPases, glucose transporters, 


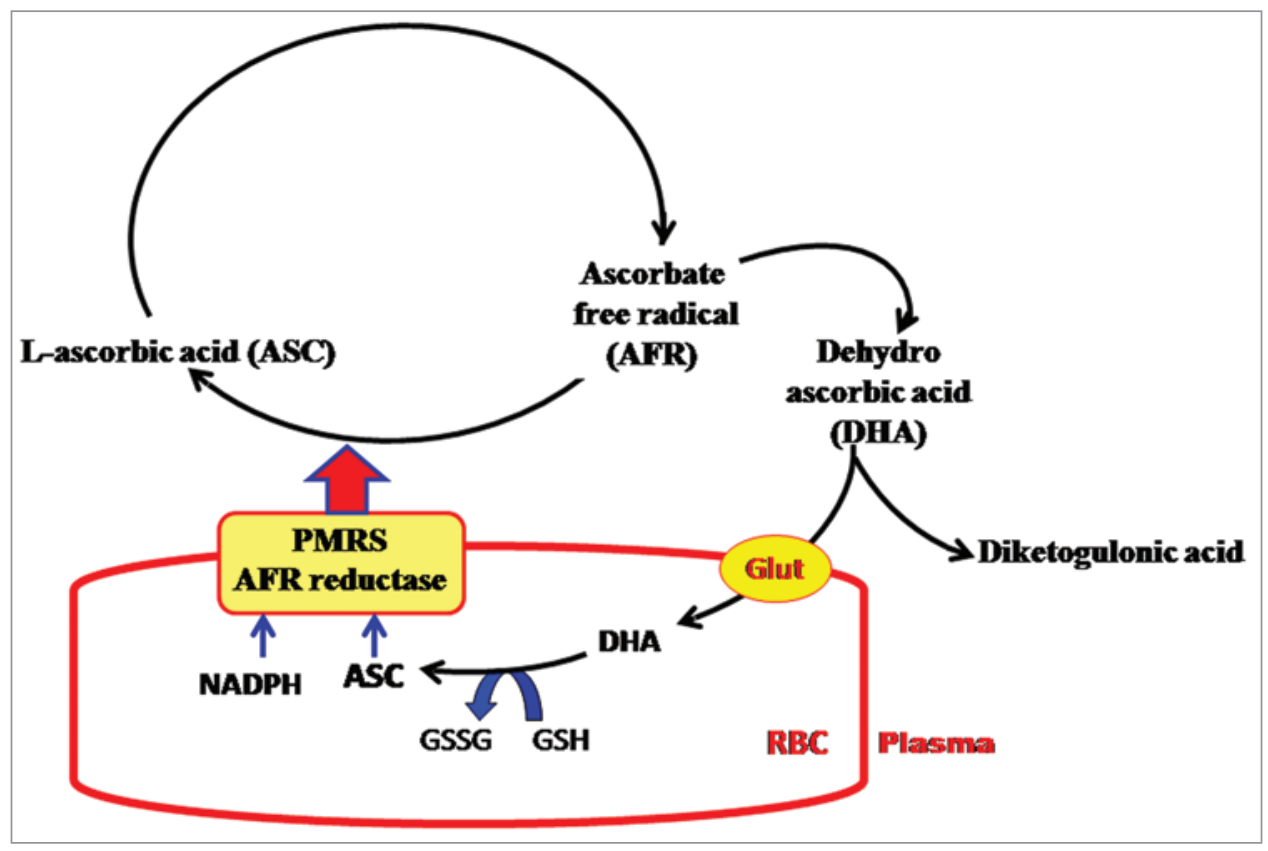

Figure 4. Schematic representation of ascorbate (ASC) recycling between erythrocytes and plasma. Under normal conditions, the plasma membrane redox system (PMRS) and ascorbate free radical (AFR) reductase function to transfer reducing equivalents from intracellular electron donors to plasma. These electrons are used to reduce the AFR to reduced ASC. During aging, the condition of oxidative stress is generated in the plasma, leading to higher rate of conversion of ASC to AFR. The increase in erythrocyte AFR reductase/PMRS activity is a compensatory mechanism to protect against increased oxidative stress (Rizvi et al. 2009).

and $\mathrm{G}$ protein-coupled receptor signaling are implicated in the pathogenesis of Alzheimer's disease. ${ }^{81}$

Recently it was investigated that the eukaryotic cells contain a plasma membrane redox system (PMRS) which contains a group of multiple oxido-reductase enzymes. ${ }^{30,81,82}$ This PMRS transfers electrons from intracellular donors nicotinamide adenine dinucleotide reduced (NADH) and/or ascorbate to extracellular acceptors. Although the exact physiologic function of this PMRS remains elusive, proposed functions include: maintenance of redox state of sulfhydryl residues in membrane proteins, neutralization of oxidative stressors outside the cells, stimulation of cell growth, recycling of $\alpha$ tocopherol, reduction of lipid hydroperoxides, reduction of ferric ion prior to iron uptake by a transferring-independent pathway and the maintenance of the extracellular concentration of ascorbic acid. ${ }^{83-85}$

The PMRS is now known to incorporate an ascorbate free radical (AFR) reductase which works to reduce extracellular AFR to ascorbate (ASC) using electrons derived from intracellular ASC through PMRS. The concerted action of erythrocyte PMRS and AFR reductase provides a mechanism for recycling of ascorbate between intracellular and extracellular compartments. ${ }^{85}$ Ascorbic acid is a well-known antioxidant present in plasma; however, only humans, higher primates and guinea pigs cannot make ASC because they lack a functional L-gulonolactone oxidase, the final enzyme of the ASC biosynthetic pathway in mammals. ${ }^{86}$ Thus, efficient mechanisms for ASC absorption, transport and recycling are important in these species. ASC is delivered to tissues through the blood, in which it is believed to be the primary antioxidant. ${ }^{87}$ In the presence of an oxidant, ASC is oxidized first to AFR and then to dehydroascorbate (DHA), which is unstable and undergoes irreversible hydrolysis to 2,3-diketo-Lgulonic acid, resulting in decreased level of the vitamin. ${ }^{88}$ Two molecules of AFR can react with each other to form one each of ASC and DHA (Fig. 4).

ASC has many different functions in humans and other mammals. In addition to its antioxidant property, this vitamin serves as a cofactor in several important enzyme reactions, including those involved in the synthesis of catecholamines, carnitine, cholesterol, amino acids and certain peptide hormones. ${ }^{89}$ Due to such a vital role in physiology and urinary loss of this vitamin, make it necessary to maintain high intracellular ASC concentration. ASC has also been shown to protect membrane and other hydrophobic compartments from oxidative damage by regenerating the antioxidant form of vitamin E. ${ }^{90}$ Ascorbate can recycle $\alpha$-tocopherol in low-density lipoprotein (LDL) in the face of an oxidant stress and thus affords protection against oxidation. Thus, recycling of ASC also helps to protect or recycle $\alpha$-tocopherol and serves to protect the erythrocyte against transmembrane oxidant stress. ${ }^{83}$ Recently it was reported that in human erythrocytes the activity of PMRS along with the AFR reductase increases with the increase in age. This activation of PMRS and AFR reductase increases the ASC recycling in human plasma and reported as a compensatory/protective mechanism that operates to maintain the ASC level in plasma and thereby minimize oxidative stress during aging. ${ }^{85}$

PMRS, also includes coenzyme Q (CoQ) and increasingly recognized as a 


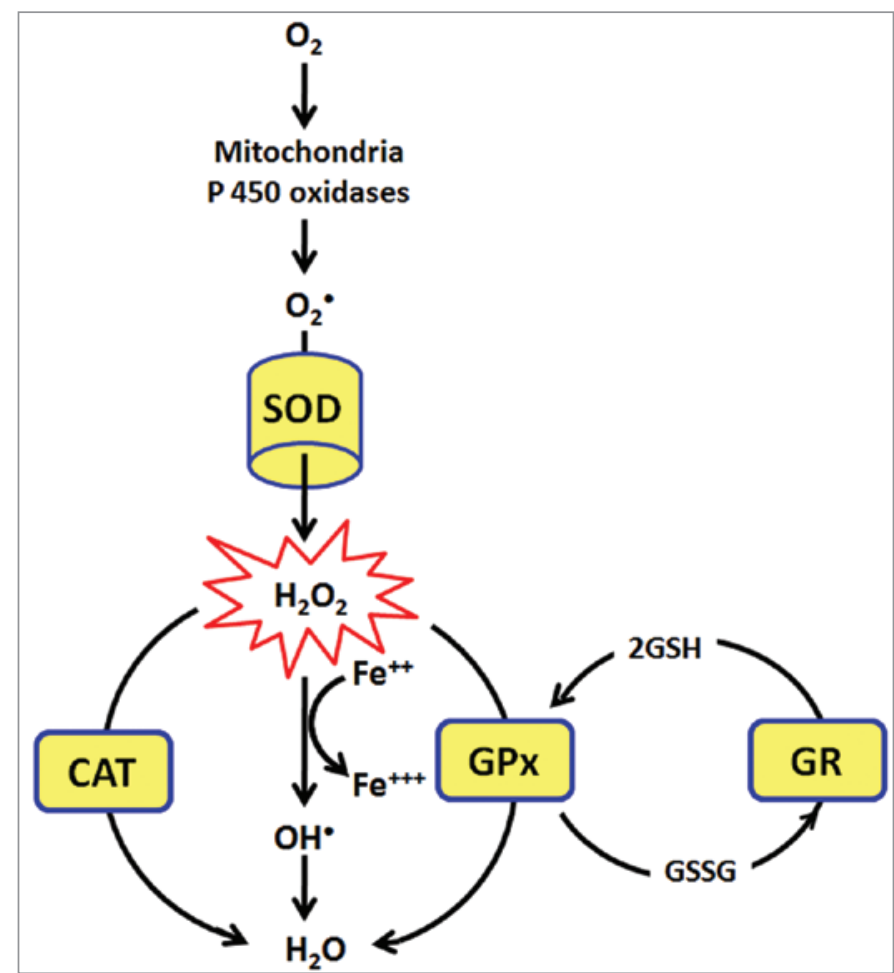

Figure 5. Superoxide dismutase (SOD), glutathione peroxidase (GPx), glutathione reductase (GR) and catalase (CAT) are the main endogenous enzymatic defense systems of all aerobic cells. They give protection by directly scavenging superoxide radicals and hydrogen peroxide, converting them to less reactive species. SOD catalyzes the dismutation of superoxide radical $\left(\bullet_{2}\right)$ to hydrogen peroxide $\left(\mathrm{H}_{2} \mathrm{O}_{2}\right)$. Although $\mathrm{H}_{2} \mathrm{O}_{2}$ is not a radical, it is rapidly converted by fenton reaction into - OH radical which is very reactive. GPx neutralizes hydrogen peroxide by taking hydrogens from two GSH molecules resulting in two $\mathrm{H}_{2} \mathrm{O}$ and one GSSG. GR then regenerates GSH from GSSG. CAT the important part of enzymatic defense, neutralizes $\mathrm{H}_{2} \mathrm{O}_{2}$ into $\mathrm{H}_{2} \mathrm{O}$.

major mechanism for reducing plasma membrane-associated oxidative stress and, in compensating for mitochondrial dysfunction, as an alternative source of ATP production by increasing NAD levels and glycolysis. ${ }^{81}$ Multiple enzymes of the PMRS are upregulated in the brain in response to caloric restriction and that these changes in the PMRS were associated with decreased markers of oxidative stress and increased levels of CoQ and $\alpha$-tocopherol. Hyun et al. ${ }^{81}$ reported that the enhancement of the PMRS is a mechanism by which caloric restriction may counteract mitochondrial dysfunction and oxidative stress in the brain during aging. These reportings emphasize the importance of PMRS and AFR reductase in human aging and possibly in other conditions which are accompanied by a decrease in plasma antioxidant status and may be an important biomarker of oxidative stress as well as aging. ${ }^{30,85}$

\section{Antioxidative Enzymatic Systems}

Several enzymes have evolved in aerobic cells to overcome the damaging effects of ROS. They are significantly used to maintain the redox balance during oxidative stress and are collectively called as endogenous antioxidative enzymes. Superoxide dismutase (SOD), glutathione peroxidase $(\mathrm{GPx})$, glutathione reductase (GR) and catalase (CAT) are the main endogenous enzymatic defense systems of all aerobic cells. ${ }^{4,91}$ They give protection by directly scavenging superoxide radicals and hydrogen peroxide, converting them to less reactive species (Fig. 5). ${ }^{92}$ SOD catalyzes the dismutation of superoxide radical $\left(\bullet \mathrm{O}_{2}\right)$ to hydrogen peroxide $\left(\mathrm{H}_{2} \mathrm{O}_{2}\right)$. Although $\mathrm{H}_{2} \mathrm{O}_{2}$ is not a radical, it is rapidly converted by fenton reaction into $\bullet \mathrm{OH}$ radical which is very reactive. Among various antioxidant mechanisms in the body, SOD is thought to be one of the major enzymes that protect cells from ROS. The liver, in particular, is very high in SOD. Cellular concentration of SOD relative to metabolic activity is a very good lifespan predictor of animal species. Most mammals experience a lifetime energy expenditure of 200,000 calories per gram, but humans have an amazing 800,000 calories per gram. ${ }^{93}$ Humans have the highest levels of SOD relative to metabolic rate of all species studied. Oxidative damage to DNA is ten times greater in rats than in humans. Maximum lifespan correlates with lower rate of free-radical production and higher rate of DNA repair. ${ }^{93}$

The SOD molecule in the cytoplasm contains copper \& zinc atoms $(\mathrm{Cu} /$ $\mathrm{Zn}$-SOD), whereas the SOD in mitochondria contains manganese (Mn-SOD). SODs have been isolated and characterized from a wide variety of organisms. One class consists of SODs with $\mathrm{Cu}(\mathrm{II})$ plus $\mathrm{Zn}$ (II) at the active site (Cu/ZnSOD), another with $\mathrm{Mn}$ (III) (MnSOD), a third with $\mathrm{Fe}$ (III) (FeSOD), and a fourth with $\mathrm{Ni}(\mathrm{II} / \mathrm{III})$ (NiSOD). Cu/ZnSODs are generally found in the cytosol of eukaryotic cells, in chloroplasts, and in some prokaryotes. $^{94}$

Glutathione peroxidase (GPx) neutralizes hydrogen peroxide by taking hydrogens from two GSH molecules resulting in two $\mathrm{H}_{2} \mathrm{O}$ and one GSSG. The enzyme glutathione reductase then regenerates $\mathrm{GSH}$ from GSSG with NADPH as a source of hydrogen. Another important part of the enzymatic defense system is catalase. CAT is one of the most active catalysts produced by nature. CAT is largely, but not exclusively, localized in peroxisomes, wherein many $\mathrm{H}_{2} \mathrm{O}_{2}$ producing enzymes reside. Thus $\mathrm{CAT}$, which exhibits a high $\mathrm{Km}$ for $\mathrm{H}_{2} \mathrm{O}_{2}$, can act upon $\mathrm{H}_{2} \mathrm{O}_{2}$ produced before it diffuses to other parts of the cell. CAT is a tetrameric heme containing enzyme that is found in all aerobic organisms. Because of its wide distribution, evolutionary conservation and capacity to rapidly degrade hydrogen peroxide, it has been proposed that CAT plays an important role in systems which have evolved to allow organisms to live in aerobic environments. ${ }^{94}$ A very interesting mechanism shown by the CAT depending upon the concentration of $\mathrm{H}_{2} \mathrm{O}_{2}$ is its dual function. CAT 


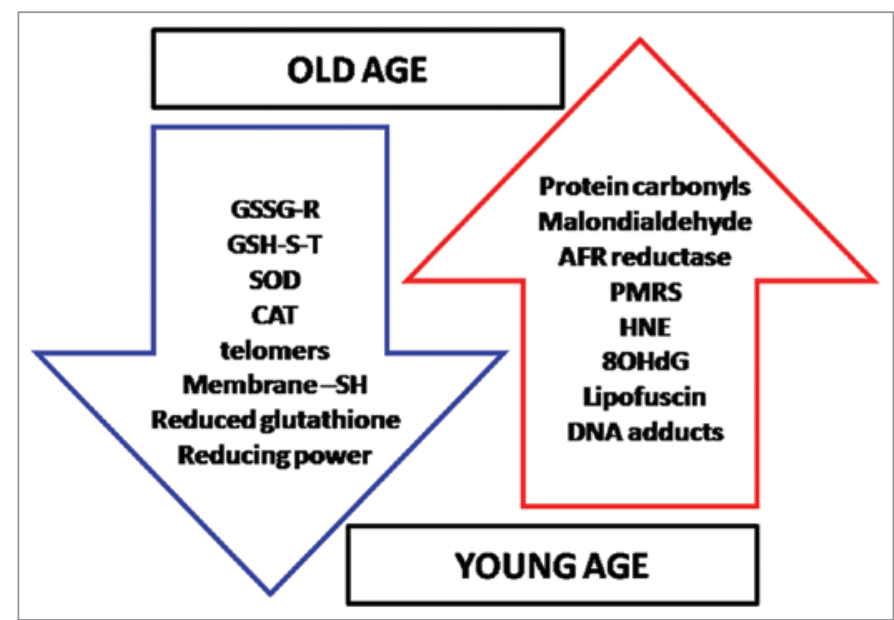

Figure 6. Status of important biomarkers of oxidative stress during aging is shown. AFR reductase; ascorbate free radical reductase, PMRS; plasma membrane redox system, HNE; 4-hydroxy-2,3-trans-nonenal, 8OHdG; 8-Hydroxy-2'deoxyguanosine, GSSG-R; glutathione reductase, GSH-S-T; glutathione S-transferase, SOD; superoxide dismutase, CAT; catalase.

neutralizes the $\mathrm{H}_{2} \mathrm{O}_{2}$ in concentration dependent manner. At low concentrations $(<1 \mu \mathrm{M})$ of $\mathrm{H}_{2} \mathrm{O}_{2}$, it acts "peroxidatically", i.e., a variety of hydrogen donors (e.g., ethanol, ascorbic acid) can be oxidized in the following manner:

$$
\mathrm{RH}_{2}+\mathrm{H}_{2} \mathrm{O}_{2} \rightarrow \mathrm{R}+2 \mathrm{H}_{2} \mathrm{O}
$$

while at higher concentrations of substrate, CAT decomposes toxic hydrogen peroxide at an extremely rapid rate using the "catalatic" reaction in which $\mathrm{H}_{2} \mathrm{O}_{2}$ acts as both an acceptor and donor of hydrogen molecules:

$$
2 \mathrm{H}_{2} \mathrm{O}_{2} \rightarrow 2 \mathrm{H}_{2} \mathrm{O}+\mathrm{O}_{2} \text {. }
$$

Another property that makes CAT unique among $\mathrm{H}_{2} \mathrm{O}_{2}$ degrading enzymes is that it degrades $\mathrm{H}_{2} \mathrm{O}_{2}$ without consuming cellular reducing equivalents. Hence, CAT provides the cell with a very energy efficient mechanism to remove hydrogen peroxide. Therefore, when cells are stressed for energy and are rapidly generating $\mathrm{H}_{2} \mathrm{O}_{2}$ through "emergency" catabolic processes, $\mathrm{H}_{2} \mathrm{O}_{2}$ is degraded by CAT in an energy-efficient manner. This results in a net gain of reducing equivalents and, therefore cellular energy. It has been proposed that CAT may be uniquely suited to regulate the homeostasis of $\mathrm{H}_{2} \mathrm{O}_{2}$ in the cell. Therefore activity of CAT is one of the important biomarker of oxidative stress.
There is a suggestion that the activity of antioxidant enzymes may play an important role in determining the life span of animal species. ${ }^{95,96}$ Most of the workers have shown the decreased activities of these enzymes during oxidative stress as well aging; ${ }^{97}$ however the activity especially in regard to SOD is still in controversy. Some researches could not detect an age related difference or they showed an increase in age. ${ }^{61,98}$ These discrepancies can be in part related to the fact that humans express different SODs. ${ }^{94}$ Gianni et al. ${ }^{99}$ discovered that there is no difference in total activity or $\mathrm{CuZn}$-SOD activity while the activity of $\mathrm{Mn}-\mathrm{SOD}$ increases with age. Same but less results have also been observed in the case of activity of CAT. Many investigations showed that the activity of CAT increases with age. ${ }^{26,98,99}$ While some investigations oppose this finding and reported no significant change in the CAT activity. ${ }^{100,101}$ The effect of aging and oxidative stress on the glutathione reductase (GR) and glutathione S-transferase (GSH-S-T) was very clear where negative correlations with age were reported. ${ }^{76,96}$ This corresponds with a shift of the glutathione system to the oxidized form.

A recent study on human plasma of Indian population has shown a significant correlation between increasing age and activity of CAT and SOD in human plasma. The activity of CAT and SOD was increased in the samples of old aged groups in comparison of the young aged samples. ${ }^{98}$ Interestingly a positive correlation was found between the antioxidant capacity of the plasma and activities of CAT and SOD. ${ }^{98}$ The increased activity of antioxidant enzymes among aged persons seems to be a compensatory mechanism against high levels of ROS in old age; perhaps this adaptability ensures that oxidation-mediated damage takes place at a rate that determines the pace at which we age, defined by Harman as the inborn aging process'. 8

\section{Conclusion}

The deleterious effects of oxidative stress generated by uncontrolled production of ROS/RNS play a very crucial role in onset of aging. Various biochemical parameters get directly affected and altered during aging (Fig. 6). Several parameters are being used to evaluate the extent of oxidative damage, however not all the parameters can be used as biomarker of aging process because many of them get influenced by several factors including sex, types of tissue, diet and also their efficient repairing. Meanwhile some parameters are also dependent upon the methods used to measure them. An increasing body of evidence point out to the importance of erythrocytes to act as model cells for the study of aging and age-related diseases. The erythrocyte provides an array of biochemical parameters which have been successfully used to assess aging related changes in redox status.

\section{Acknowledgements}

K.B.P. is recipient of Senior Research Fellowship form Council of Scientific \& Industrial Research (CSIR), India. S.I.R. acknowledges the support from UGC, New Delhi, India.

\section{References}

1. Rattan SIS. Theories of biological aging: Genes, proteins and free radicals. Free Radic Res 2006; 40:10-2

2. Harman D. Origin and evolution of the free radical theory of aging: a brief personal history, 1954-2009. Biogerontology 2009; 9234-2.

3. Droge W. Free radicals in the physiological control of cell function. Physiol Rev 2002; 82:47-95.

4. Halliwell B, Gutteridge JMC. Cellular responses to oxidative stress: adaptation, damage, repair, senescence and death. In: Free Radicals in Biology and Medicine. $4^{\text {th }}$ ed. New York: Oxford University Press 2007; 187-267. 
5. Elahi MM, Kong YX, Matata BM. Oxidative stress as a mediator of cardiovascular disease. Oxid Med Cell Longev 2009; 2:259-69.

6. Junqueira VB, Barros SB, Chan SS, Rodrigues L, Giavarotti L, Abud RL, Deucher GP. Aging and oxidative stress. Mol Aspects Med 2004; 25:5-16.

7. Harman D. Ageing: A theory based on free radical and radiation chemistry. J Gerontol 1956; 11:298300 .

8. Harman D. Free radical theory of aging: An update Ann N Y Acad Sci 2006; 1067:1-12.

9. Dalton TP, Shertzer HG, Puga A. Regulation of gene expression by reactive oxygen. Ann Rev Pharmaco Toxicol 1999; 39:67-101

10. Jha R, Rizvi SI. Age-dependent decline in erythrocyte acetylcholinesterase activity: correlation with oxidative stress. Biomed Pap Med Fac Univ Palacky Olomouc Czech Repub 2009; 153:195-8.

11. Karabulut I, Balkanci ZD, Pehlivanoglu B, Erdem A, Fadillioglu E. Effect of toluene on erythrocyte membrane stability under in vivo and in vitro conditions with assessment of oxidant/antioxidant status. Toxicol Ind Health 2009; 25:545-50.

12. Pandey KB, Mishra N, Rizvi SI. Myricetin may provide protection against oxidativestress in type 2 diabetic erythrocytes. Z Naturforsch C 2009; 64:626-30

13. Saxena RK, Khandelwal S. Aging and destruction of blood erythrocytes in mice. Current Sci 2009; 97:500-7.

14. Sivilotti ML. Oxidant stress and haemolysis of the human erythrocyte. Toxicol Rev 2004; 23:169-88.

15. Vacha J. Red cell life-span. In Agar NS, Board PG, eds. Red blood cells of domestic animals. Elsevier $1983 ; 67-132$

16. Werre JM, Willekens FLA, Bosch FH, De Haan LD, Van der Vegt SGL, Van den Bos AG, Bosman GJCGM. The red cell revisited: matters of life and death. Cell Mol Biol 2004; 50:139-45.

17. Willekens FLA, Bos HJ, Roerdinkholder-Stoelwinder B, Groenen-Döpp YAM, Van Willekens FLA, Bosch $\mathrm{FH}$, et al. Quantification of loss of haemoglobin components from the circulating red blood cell in vivo. Eur J Haematol 1997; 58:246-50.

18. Lenaz $\mathrm{G}$. The mitochondrial production of reactive oxygen species: Mechanism and implications in human pathology. IUBMB Life 2001; 52:159-64.

19. Harper ME, Bevilacqua L, Hagopian K, Weindruch R, Ramsey JJ. Aging, oxidative stress and mitochondrial uncoupling. Acta Physiol Scand 2004; 182:321

20. Aquino R, Morelli S, Lauro MR, Abdo S, Saija A, Tomaino A. Phenolic constituents and antioxidant activity of an extract of Anthurium versicolor leaves. J Nat Prod 2001; 64:1019-23.

21. Alzoreky N, Nakahara K. Antioxidant activity of some edible Yemeni plants evaluated by Ferrylmyoglobin/ ABTS $^{+}$assay. Food Sci Technol Res 2001; 7:141-4.

22. Banerjee D, Madhusoodanan UK, Sharanabasappa M, Ghosh S, Jacob J. Measurement of plasma hydroperoxide concentration by FOX-1 assay in conjunction with triphenylphosphine. Clin Chim Acta 2003; 337:147-52.

23. Cao G, Prior RL. Measurement of oxygen radical absorbance capacity in biological samples. Methods Enzymol 2002; 299:50-62.

24. Pryor WA, Cornicelli JA, Devall LJ, Tait B, Trivedi BK, Witiak DT, Wu M. A rapid screening test to determine the antioxidant potencies of natural and synthetic antioxidant. J Org Chem 1993; 58:352132.

25. Benzie IFF, Strain JJ. The ferric reducing ability of plasma (FRAP) as a measure of "antioxidant power": The FRAP assay. Anal Biochem 1996; 239:70-6.

26. Inal ME, Kanbak G, Sunal E. Antioxidant enzyme activities and malondialdehyde levels related to aging. Clin Chim Acta 2001; 305:75-80.
27. Melov S. Animal models of oxidative stress, aging and therapeutic antioxidant interventions. Int J Biochem Cell Biol 2002; 34:1395-400.

28. Stadtman ER. Importance of individuality in oxidative stress and aging. Free Radic Biol Med 2002; 33:597-604.

29. Bonnefont-Rousselot D, Therond P, Beaudeux JL, Peynet J, Legrand A, Delattre J. Aging and oxidative stress. Which potential markers? Ann Biol Clin 2001; 59:453-9.

30. Rizvi SI, Jha R, Maurya PK. Erythrocyte plasma membrane redox system in human aging. Rejuvenation Res 2006; 9:470-4.

31. Pandey KB, Rizvi SI. Plant polyphenols as dietary antioxidants in human health and disease. Oxid Med Cell Longev 2009; 2:1-9.

32. Cao G, Booth SL, Sadowski JA, Prior RL. Increases in human plasma antioxidant capacity after consumption of controlled diets high in fruit and vegetables. Am J Clin Nutr 1998; 68:1081-7.

33. Hadi AH, Abdolamir A, Mahtab H, Abolfazl D, Yusef R. Influence of plasma total antioxidant ability on lipid and protein oxidation products in plasm and erythrocyte ghost obtained from developing and adult rats pretreated with two vitamin $\mathrm{K}$ formulations. Mol Cell Biochem 2004; 267:195-201.

34. Li XM, Shi YH, Wang F, Wang HS, Le GW. In vitro free radical scavenging activities and effect of synthetic oligosaccharides on antioxidant enzyme and lipid peroxidation in aged mice. J Pharm Biomed Anal 2007; 43:364-70.

35. Siems W, Grune T. Lipid peroxidation measurement methodological approaches and clinical importance. In: Grune T, ed. Free radicals and diseases: gene expression, cellular metabolism and pathophysiol ogy. Vol. 367. Amsterdam, Berlin, Oxford, Tokyo, Washington, DC: Series I: Life and Behavioura Sciences. IOS Press NATO Science Series 2005; 11-21

36. Walling C. Free radicals in solution. Wiley, New York 1955.

37. Niki E. Free radicals in the 1900's: from in vitro to in vivo. Free Radic Res 2000; 33:693-704.

38. Niki E. Lipid peroxidation: Physiological levels and dual biological effects. Free Radic Biol Med 2009; 47:469-84

39. Greenberg ME, Li XM, Gugiu BG, Gu X, Qin J, Salomon RG, Hazen SL. The lipid whisker mode of the structure of oxidized cell membranes. J Bio Chem 2008; 283:2385-96.

40. West JD, Marnett LJ. Endogenous reactive intermediates as modulators of cell signaling and cell death Chem Res Toxicol 2006; 19:173-94.

41. Lee J, Koo N, Min DB. Reactive oxygen species, aging and antioxidative nutraceuticals. Comprehens Rev Food Sci Food Safety 2004; 3:21-33.

42. Rizvi SI, Maurya PK. Markers of oxidative stress in erythrocytes during aging in humans. Ann N Y Acad Sci 2007; 1100:373-82.

43. Pandey KB, Mishra N, Rizvi SI. Protective role of myricetin on markers of oxidative stress in human erythrocytes subjected to oxidative stress. Nat Prod Commun 2009; 4:221-6.

44. Kingsley M, Cunningham D, Mason L, Kilduff LP, McEneny J. Role of creatine supplementation on exercise-induced cardiovascular function and oxidative stress. Oxid Med Cell Longev 2009; 2: 247-54.

45. Sanz A, Pamplona R, Barja G. Is the mitochondrial free radical theory of aging intact? Antioxid Redox Signal 2006; 8:582-99.

46. Esterbauer $\mathrm{H}$, Cheeseman $\mathrm{KH}$. Determination of aldehydic lipid peroxidation products: malondialdehyde and 4-hydroxynonenal. Methods Enzymo $1990 ; 186: 407-13$.

47. Gil L, Siems W, Mazurek B, Gross J, Schroeder P, Voss P, Grune T. Age associated analysis of oxidative stress parameters in human plasma and erythrocytes. Free Radic Res 2006; 40:405-505.
48. Hawkins CL, Morgan PE, Davies MJ. Quantification of protein modification by oxidants. Free Radic Biol Med 2009; 46:965-88.

49. Berlett BS, Stadtman ER. Protein oxidation in aging, disease and oxidative stress. J Biol Chem 1997; 272:20313-6.

50. Poon HF, Calabrese V, Scapagnini G, Butterfield DA. Free radicals and brain aging. Clin Geriatr Med 2004; 20:329-59.

51. Witko-Sarsat V, Friedlander M, Capeillère-Blandin C, Nguyen-Khoa T, Nguyen AT, Zingraff J, et al. Advanced oxidation protein products as a novel marker of oxidative stress in uremia. Kidney Int 1996; 49:1304-13

52. Levine RL, Garland D, Oliver CN, Amici A, Climent I, Lenz AG, et al. Determination of carbonyl content in oxidatively modified proteins. Methods Enzymol 1990; 186:464-79.

53. Uchida K, Stadtman ER. Covalent attachment of 4-hydroxynonenal to glyceraldehyde-3-phosphate dehydrogenase. A possible involvement of intra- and intermolecular cross-linking reaction. J Biol Chem 1993; 268:6388-93.

54. Kristal BS, Yu BP. An emerging hypothesis: synergistic induction of aging by free radicals and Maillard reactions. J Gerontol 1992; 47:107-14.

55. Bryszewska M, Zavodnik IB, Niekurzale A, Szosland $\mathrm{K}$. Oxidative processes in red blood cells from normal and diabetic individuals. Biochem Mol Biol Int 1995; 37:345-54

56. Pandey KB, Rizvi SI. Protective effect of resveratrol on formation of membrane protein carbonyls and lipid peroxidation in erythrocytes subjected to oxidative stress. Appl Physiol Nutr Metab 2009; 34:1093-

57. Pandey KB, Rizvi SI. Protection of protein carbonyl formation by quercetin in erythrocytes subjected to oxidative stress. Med Chem Res 2009; In press.

58. Floyd RA, Hensley K. Oxidative stress in brain aging. Implications for therapeutics of neurodegenerative diseases. Neurobiol Aging 2002; 23:795-807.

59. Stadtman E. Protein oxidation in aging and agerelated diseases. Ann NY Acad Sci 2001; 298:22-38.

60. Mutlu-Turkoglu U, Ilhan E, Oztezcan S, Kuru A, Aykac-Toker G, Uysal M. Age-related increase in plasma malondialdehyde and protein carbonyl levels and lymphocyte DNA damage in elderly subjects. Clin Biochem 2003; 36:397-400.

61. Voss P, Siems W. Clinical oxidation parameters of aging. Free Radic Res 2006; 40:1339-49.

62. Dalle-Donne I, Rossi R, Giustarini D, Milzani A, Colombo R. Protein carbonyl groups as biomarkers of oxidative stress. Clin Chim Acta 2003; 329:23-38.

63. Wu G, Fang YZ, Yang S, Lupton JR, Turner ND. Glutathione metabolism and its implications for health. J Nutr 2004; 134:489-92.

64. Zhu Y, Carvey PM, Ling Z. Age-related changes in glutathione and glutathione-related enzymes in rat brain. Brain Res 2006; 1090:35-44.

65. Jones DP. Extracellular redox state: refining the definition of oxidative stress in aging. Rejuvenation Res 2006; 9:169-81.

66. Manson RP. Free radicals metabolites of foreign compounds and their toxicological significance. In: Hodgson E, Bend JR, Philpot RM, eds. Reviews in biochemical toxicology. Amsterdam: Elsevier 1979; 151-200.

67. Meister A. Glutathione deficiency produced by inhibition of its synthesis, and its reversal; Applications in research and therapy. Pharmacol Ther 1991; 51:15594.

68. Mitchell JB, Russo A. The role of glutathione in radiation and drug induced cytotoxicity. $\mathrm{Br} \mathrm{J}$ Cancer 1987; 55:96-104.

69. Estrela JM, Obrador E, Navarro J, Lasso-de-la-Vega MC, Pellicer JA. Elimination of Ehrlich tumours by ATPinduced growth inhibition, glutathione depletion and X-rays. Nat Med 1995; 1:84-8. 
70. Sies H. Biochemistry of oxidative stress. Angewandte Chem 1986; 25:1058-71.

71. Willson RL. Free radical repair mechanisms and the interactions of glutathione and vitamins $\mathrm{C}$ and $\mathrm{E}$. In: Nygaard OF, Simic MG, eds. Radioprotectors and anticarcinogens. New York: Academic Press 1983; $1-22$.

72. Hercbergs A, Brook-Simoni F, Holtzman F, Bar-Am J, Leith JT, Brenner HJ. Erythrocyte glutathione and tumour response to chemotherapy. Lancet 1992; 339:1074-6.

73. Menendez CE, Hacker P, Sonnenfeld M, McConnell $\mathrm{R}$, Rivlin RS. Thyroid hormone control of glutathione reductase activity in rat erythrocytes and liver. Am J Physiol 1974; 226:1480-3.

74. Cimino JA, Jhangiani S, Schwartz E, Cooperman JM. Riboflavin metabolism in the hypothyroid human adult. Proc Soc Exp Biol Med 1987; 184:1513.

75. Gohil K, Vigui C, Stanley WC, Brooks G, Packer L. Blood glutathione oxidation during human exercise. J Appl Physiol 1988; 64:115-9.

76. Erden-Inal M, Sunal E, Kanbak G. Age-related changes in the glutathione redox system. Cell Biochem Funct 2002; 20:61-6.

77. Andriollo-Sanchez M, Hininger-Favier I, Meunier N, Venneria E, O'Connor JM, Maiani G, et al. Agerelated oxidative stress and antioxidant parameters in middle-aged and older European subjects: the ZENITH study. Eur J Clin Nutr 2005; 59:58-62.

78. Reglinski J, Hoey S, Smith WE, Sturrock RD. Cellular response to oxidative stress at sulphydryl group receptor sites on the erythrocytes membrane. J Biol Chem 1988; 263:12360-6.

79. Wang X, Wu Z, Song G, Wang H, Long M, Cai $S$. Effects of oxidative damage of membrane protein thiol group on erythrocyte membrane microviscoelasticities. Clin Hemorheol Microcirc 1999; 21:137-46.

80. Mattson MP. Modification of ion homeostasis by lipid peroxidation: roles in neuronal degeneration and adaptive plasticity. Trends Neurosci 1998; 21:53-
81. Hyun DH, Emerson SS, Jo DG, Mattson MP, de Cabo R. Calorie restriction upregulates the plasma membrane redox system in brain cells and suppresses oxidative stress during aging. Proc Natl Acad Sci USA 2006; 103:19908-12.

82. Su D, May JM, Koury MJ, Asard H. Human erythrocyte membranes contain a cytochrome b561 that may be involved in extracellular ascorbaterecycling. J Biol Chem 2006; 281:39852-9.

83. VanDuijn MM, Van den Zee J, VanSteveninck J, Van den Broek PJA. Ascorbate stimulates ferricyanide reduction in HL-60 cells through a mechanism distinct from the NADH-dependent plasma membrane reductase. J Biol Chem 1998; 273:13415-20.

84. May JM, Qu ZC, Cobb CE. Human erythrocyte recycling of ascorbic acid. J Biol Chem 2004; 279:14975-82.

85. Rizvi SI, Pandey KB, Jha R, Maurya PK. Ascorbate recycling by erythrocytes during aging in humans. Rejuvenation Res 2009; 12:3-6.

86. Nishikimi M, Fukuyama R, Minoshima S, Shimizu $\mathrm{N}$, Yagi K. Cloning and chromosomal mapping of the human nonfunctional gene for L-gulonogamma-lactone oxidase, the enzyme for L-ascorbic acid biosynthesis missing in man. J Biol Chem 1994; 269:13685-8.

87. Frei B, England L, Ames BN. Ascorbate is an outstanding antioxidant in human blood plasma. Proc Natl Acad Sci USA 1989; 86:6377-81.

88. Deutsch JC. Oxygen-accepting antioxidants which arise during ascorbate oxidation. Anal Biochem 1998; 260:223-9.

89. Harrison FE, May JM. Vitamin C function in the brain: vital role of the ascorbate transporter SVCT2 Free Radic Biol Med 2009; 46:719-30.

90. Packer JE, Slater TF, Wilson RL. Direct observation of a free radical interaction between vitamin $\mathrm{E}$ and vitamin C. Nature 1979; 278:737-8.

91. Fisher-Wellman K, Bell HK, Bloomer RJ. Oxidative stress and antioxidant defense mechanisms linked to exercise during cardiopulmonary and metabolic disorders. Oxid Med Cell Longev 2009; 2:43-51.
92. Milic VD, Stankov K, Injac R, Djordjevic A, Srdjenovic B, Govedarica B, et al. Activity of antioxidative enzymes in erythrocytes after a single dose administration of doxorubicin in rats pretreated with fullerenol C(60)(OH)(24). Toxicol Mech Methods 2009; 19:24-8

93. Perez-Campo R, López-Torres M, Cadenas S, Rojas $\mathrm{C}$, Barja G. The rate of free radical production as a determinant of the rate of aging: evidence from the comparative approach. J Comp Physiol B 1998; 168:149-58.

94. Scandalios JG. Oxidative stress: molecular perception and transduction of signals triggering antioxidant gene defenses. Br J Med Biol Res 2005; 38:9951014 .

95. Saraymen R, Kilic E, Yazar S, Cetin M. Influence of sex and age on the activity of antioxidant enzymes of polymorphonuclear leukocytes in healthy subjects. Yonsei Med J 2003; 44:9-14.

96. Ceballos-Picot I, Triveier JM, Nicole A, Sinet PM, Thevenin M. Age-correlated modifications of copperzinc superoxide dismutase and glutathione-related enzyme activities in human erythrocytes. Clin Chem 1992; 38:66-70.

97. Tokunage K, Kanno K, Ochi M, Nishimiya T, Shishino K, Murase M, et al. Lipid peroxide and antioxidants in the elderly. Rinsho Byori 1998; 46:783-

98. Rizvi SI, Maurya PK. Alterations in antioxidant enzymes during aging in humans. Mol Biotechnol 2007; 37:58-61.

99. Gianni P, Jan KJ, Douglas MJ, Stuart PM, Tarnopolsky MA. Oxidative stress and mitochondrial theory of aging in human skeletal muscle. Exp Gerontol 2004; 39:1391-400.

100.Barnett YA, King CM. An investigation of antioxidant status, DNA repair capacity and mutation as a function of age in humans. Mutat Res 1995 338:115-28.

101. Kasapogul M, Ozben T. Alterations of antioxidant enzymes and oxidative stress markers in aging. Exp Gerontol 2001; 36:209-20. 


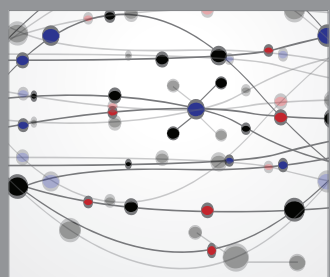

The Scientific World Journal
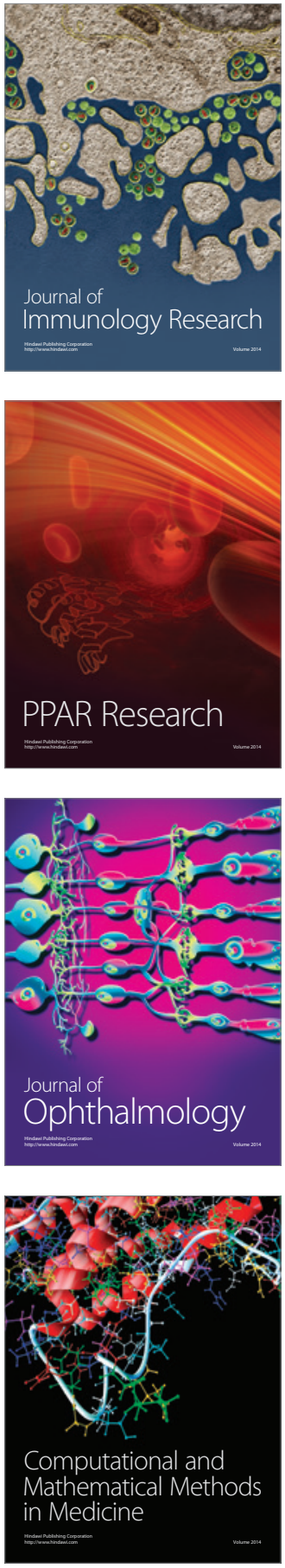

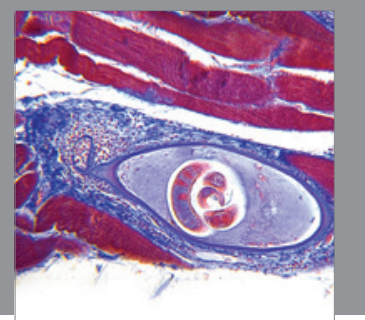

Gastroenterology

Research and Practice
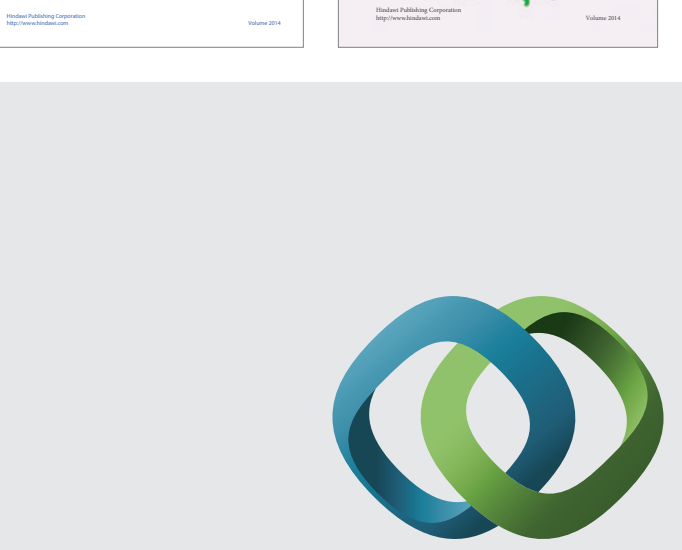

\section{Hindawi}

Submit your manuscripts at

http://www.hindawi.com
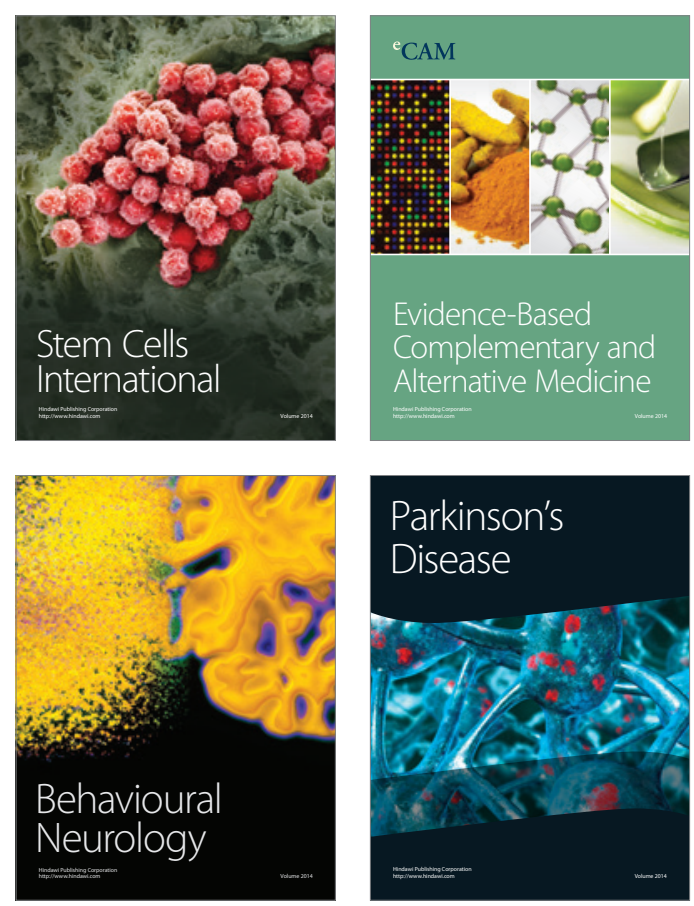

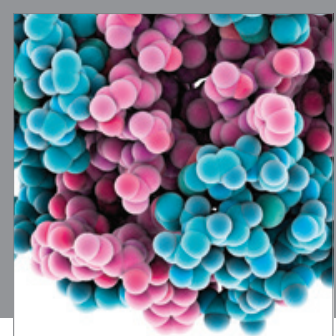

Journal of
Diabetes Research

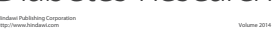

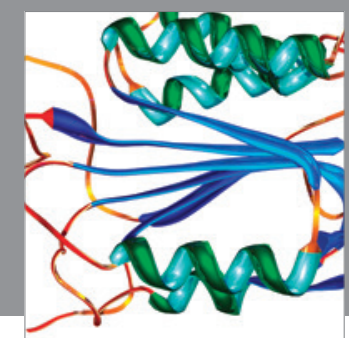

Disease Markers
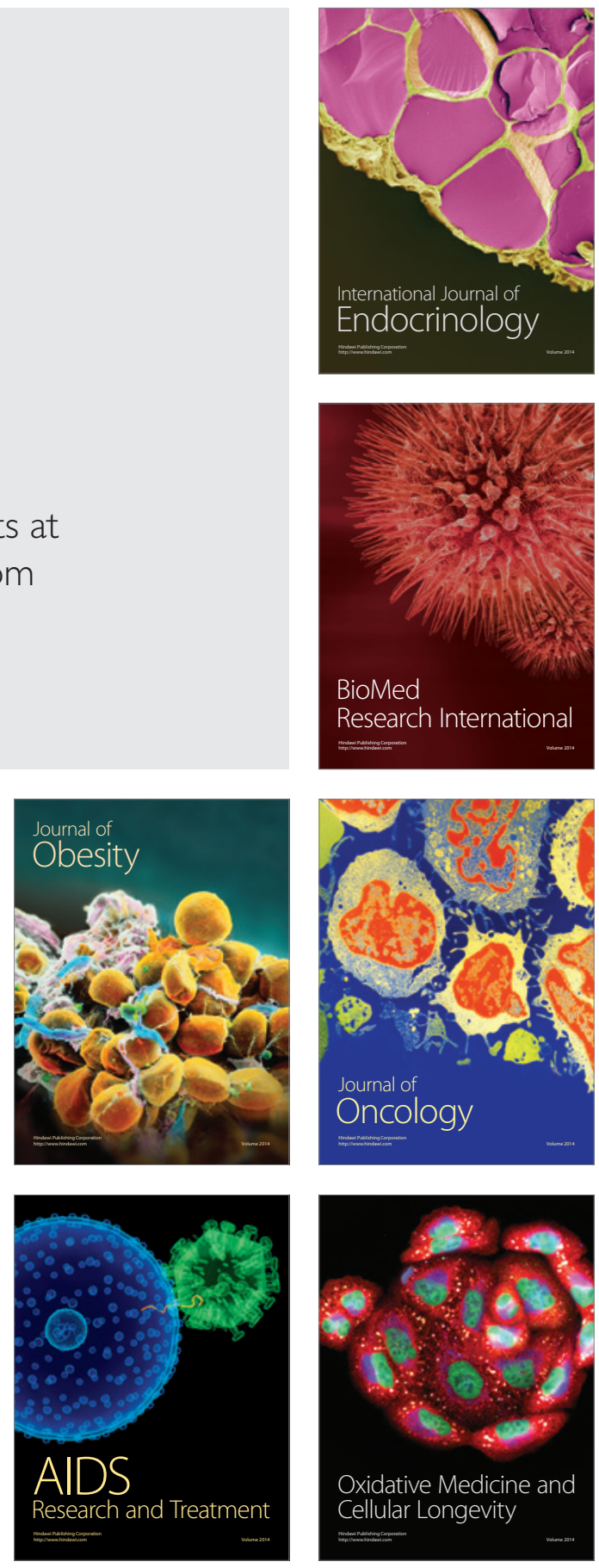